\title{
Examination of Post-discharge Follow-up Appointment Status and 30-Day Readmission
}

\author{
Kevin Coppa, BS ${ }^{7}$, Eun Ji Kim, MD, MS, MS ${ }^{2,3}$, Michael I. Oppenheim, MD ${ }^{1,2}$, \\ Kevin R. Bock, MD, MHCDS ${ }^{1,4}$, Joseph Conigliaro, MD, MPH ${ }^{2,3}$, and Jamie S. Hirsch, MD, \\ $M A, M S B^{1,2,3}$
}

\begin{abstract}
'Department of Information Services, Northwell Health, Lake Success, NY, USA; ${ }^{2}$ Department of Medicine, Donald and Barbara Zucker School of Medicine at Hofstra/Northwell, Hempstead, NY, USA; ${ }^{3}$ nstitute of Health Innovations and Outcomes Research, Feinstein Institutes for Medical Research, Manhasset, NY, USA; ${ }^{4}$ Department of Pediatrics, Donald and Barbara Zucker School of Medicine at Hofstra/Northwell, Hempstead, NY, USA.
\end{abstract}

BACKGROUND: Post-hospital discharge follow-up appointments are intended to evaluate patients' recovery following a hospitalization, but it is unclear how appointment statuses are associated with readmissions.

OBJECTIVE: To examine the association between postdischarge ambulatory follow-up status, (1) having a scheduled appointment and (2) arriving to said appointment, and 30-day readmission.

DESIGN AND SETTING: A retrospective cohort study of patients hospitalized at 12 hospitals in an Integrated Delivery Network and their ambulatory appointments in that same network.

PATIENTS AND MAIN MEASURES: We included 50,772 patients who had an ambulatory appointment within 18 months of an inpatient admission in 2018. Primary outcome was readmission within 30 days postdischarge.

KEY RESULTS: There were 32,108 (63.2\%) patients with scheduled follow-up appointments and 18,664 (36.8\%) patients with no follow-up; 28,313 (88.2\%) patients arrived, 3149 (9.8\%) missed, and 646 (2.0\%) were readmitted prior to their scheduled appointments. Overall 30-day readmission rate was 7.3\%; 6.0\% [5.75-6.31] for those who arrived, 8.8\% [8.44-9.25] for those without follow-up, and 10.3\% [9.28-11.40] for those who missed a scheduled appointment $(p<0.001)$. After adjusting for covariates, patients who arrived at their appointment in the first week following discharge were significantly less likely to be readmitted than those not having any followup scheduled (medical adjusted hazard ratio (aHR) 0.57 [0.47-0.69], $p<0.001$; surgical aHR 0.58 [0.44-0.75], $p<$ $0.001)$ There was an increased risk at weeks 3 and 4 for medical patients who arrived at a follow-up compared to those with no follow-up scheduled (week 3 aHR 1.29 [1.10-1.51], $p=0.001$; week 4 aHR 1.46 [1.26-1.70], $p<$ $0.001)$.

CONCLUSIONS: The benefit of patients arriving to their post-discharge appointments compared with patients who missed their follow-up visits or had no follow-up scheduled, is only significant during first week post-discharge, suggesting that coordination within 1 week of

Received April 26, 2020

Accepted December 29, 2020

Published online January 19, 2021 discharge is critical in reducing 30-day readmissions.

$\mathrm{J}$ Gen Intern Med 36(5):1214-21

DOI: $10.1007 / \mathrm{s} 11606-020-06569-5$

(c) Society of General Internal Medicine 2021

\section{INTRODUCTION}

Ambulatory follow-up appointments are intended to evaluate patients' recovery following a hospitalization and adjust treatments if necessary. In the event of a post-discharge complication, a well-timed follow-up appointment may prevent a costly hospital readmission arising from medication discrepancy or acute decompensation. ${ }^{1,2}$ However, follow-up appointments are underutilized, while an estimated $\$ 17.4$ billion per year was spent on readmissions for Medicare patients during the last decade. ${ }^{3}$ The Centers for Medicare and Medicaid Services (CMS) have implemented the Hospital Readmission Reduction Program and applied payment reductions to hospitals that do not meet the expected 30-day readmission rates in specified patient populations. $^{4}$ Because of these consequences, hospital administrators and healthcare providers alike have made and prioritized efforts to reduce 30-day hospital readmission rates. ${ }^{5-8}$

Improving discharge planning, patient education, and medication reconciliation are a few of the interventions aimed at reducing readmission rates. ${ }^{9-12}$ Timely follow-up with a primary care physician can reduce the risk of readmission, but this has been proven only in specific patient populations. ${ }^{13-16}$ Patients with congestive heart failure and atrial fibrillation have been shown to benefit from an early post-discharge follow-up, ${ }^{17,18}$ yet aggressive follow-up for patients with myocardial infarction did not significantly lower readmission rates. ${ }^{19}$ Overall, the impact of ambulatory follow-up appointments on 30-day readmission rates is inconsistent. ${ }^{9,15,20-24}$ One limitation of the current literature is that prior studies, which have been largely based on billing data, are only able to ascertain whether a patient arrived at a follow-up appointment or not. The scheduled status for a patient-i.e., whether the patient actually had an appointment, but missed it — has been largely unavailable. As patients who have a scheduled appointment may bypass navigating healthcare systems 
compared to those with no appointment scheduled, this is an important element to consider in readmission risk assessments.

The intent of this study is to examine the association between different types of post-discharge follow-up statuses and 30-day readmission risk using a large health system electronic health record. Specifically, we aimed to assess the readmission risk of (1) having a scheduled appointment and (2) arriving to said appointment. We hypothesize that those who arrive at scheduled appointments have lower 30-day readmission compared to those who either miss scheduled appointments or do not have scheduled appointments. Additionally, we hypothesize that those patients who miss a scheduled appointment have the highest risk of hospital readmission. We also examined the association of post-discharge follow-up timing with 30 -day readmission, by evaluating readmission rates at 7, 14, 21 , and 28 days post-hospitalization.

\section{METHODS}

\section{Data Source}

Data for this study was obtained from the enterprise inpatient electronic health record (EHR; Sunrise Clinical Manager, Allscripts, Chicago, IL), which covers 13 of the hospitals from a large health system in New York, and the enterprise ambulatory EHR (Touchworks, Allscripts, Chicago, IL), which is used at over 450 ambulatory locations.

\section{Study Population}

In order to assess the association between ambulatory appointment status and 30-day readmission risk, we queried the inpatient EHR database to obtain data on inpatient admissions in 2018. We excluded admissions to the obstetrics, psychiatry, and hospice or palliative care services, patients under the age of 21 , and admissions lasting less than 24 hours. Inpatient admissions were excluded from the dataset if the patient died during the index hospitalization or within 30 days of discharge. For patients with multiple hospitalizations, one inpatient admission was randomly chosen as the index in order to avoid overrepresentation of patients with multiple readmissions.

Data on follow-up visits within 30 days of discharge were obtained from the ambulatory EHR database. The health system Enterprise Master Patient Index was used to link patients' inpatient admissions with their ambulatory visits. We included patients who had at least one visit at a health system ambulatory primary care or specialist location using the ambulatory EHR in the 18 months prior to their first admission of 2018 . We chose to include only these patients in order to investigate a population who previously received ambulatory care within the integrated delivery network and are therefore more likely to have consistent follow-up within the health system. The ambulatory data collected included visits from July 1, 2016 (18 months prior to the earliest possible admission date), to January 30, 2019 (30 days after the last possible discharge date).

\section{0-Day Readmission and Post-discharge Fol- low-up}

The primary outcome was all-cause unplanned hospital readmission within 30 days following hospital discharge. Using the date of a patient's index admission, we created a binary marker that identified subsequent admissions leading to a 30day readmission. We excluded planned readmissions from the analysis. We used the discharge disposition to identify index visits that ended with a planned readmission prospectively, and we used the admission source code to identify visits where the admission was planned or scheduled (these are standard markers in the health system to identify planned or unplanned readmissions).

For post-discharge follow-up, each patient had one of the following follow-up appointment statuses: 1) follow-up appointment scheduled and arrived, 2) follow-up appointment scheduled and missed, and 3) follow-up not scheduled. We included the following ambulatory appointment types: return patient appointments, new patient appointments, postoperative appointments, and hospital follow-up appointments. The appointment statuses were dichotomized into either arrived or missed (the latter regardless of a coded "no show" or previous cancellation). We excluded appointments that were left as pending after the appointment date had passed. For patients with multiple follow-up appointments within 30 days of discharge, all qualifying appointments were included. Patients with multiple follow-up appointments were given a status of arrived provided they arrived to at least one of their scheduled appointments, even if others were missed.

\section{Covariates}

Demographic and clinical features associated with 30-day readmissions were obtained, including patient gender, age, race/ethnicity, LACE index, discharge disposition, length of stay, inpatient service specialty, and facility type (tertiary versus community hospital). ${ }^{14,18,25}$ Race and ethnicity was categorized to non-Hispanic White, non-Hispanic Black, Hispanic, Asian, and Other. The LACE index has been used to predict the risk of unplanned readmission within 30 days after hospital discharge in both medical and surgical patients. ${ }^{26} \mathrm{We}$ looked at each component of the LACE index when examining differences between patient groups: length of stay of the index admission (L component), acuity of the admission (A component), comorbidities (C component), and number of Emergency Department visits within the last 6 months (E component). The overall summed LACE score was used in the analyses.

\section{Statistical Analysis}

We first described patients' characteristics by (1) appointment scheduled status and (2) appointment arrival status. These characteristics are reported as number with percentage or mean with standard deviation, where appropriate. We used 
the chi-squared test for categorical variables and KruskalWallis for continuous variables across all groups to test for differences by appointment scheduled status and appointment arrival status. For multivariate analysis, we used a Cox proportional hazard model with time-varying covariates (postdischarge week of appointment) to calculate the effect of variables on the time to 30 -day readmission. ${ }^{25}$ Patients who were readmitted prior to their scheduled follow-up visit were excluded from this analysis. Most patients are not readmitted within the 30-day follow-up period and their data produce censored observations. The Schoenfeld residuals test the independence between residuals and time and hence test the proportional hazard assumption in the Cox model. ${ }^{27}$ We used a step function in order to adjust for the non-proportional effect of a patient's appointment status on readmission. Because the readmission rates between the medical and surgical patient populations were significantly different, we stratified the analysis on the inpatient service. We converted the discharge disposition to a binary variable equal to 1 if the patient was discharged home and 0 for other discharge dispositions. We also grouped the principal discharge diagnosis into standard ICD-10 diagnosis code groups. There was no missing data and all of the models satisfied the proportional hazards assumption. We also performed a sensitivity analysis to examine whether the results were consistent when we included patients who did not have ambulatory care within the past 18 months at the health system. This analysis allowed inclusion of new patients and established patients who did not seek medical care within the past 18 months. All analyses were performed using the $\mathrm{R}$ programming language, version 3.5.0
(R Foundation for Statistical Computing, Vienna, Austria). The R packages used for analysis include dplyr, ggplot2, tableone, lubridate, survival, and survminer. ${ }^{28-32} \mathrm{~A} p$ value $<$ 0.05 was considered significant. This study was approved by the Northwell Health Institutional Review Board.

\section{RESULTS}

We identified 50,772 patients who had both an inpatient admission in 2018 and an ambulatory appointment with a primary care provider or specialist within the 18 months prior to their first admission of 2018 (Fig. 1). The final cohort consisted of $32,108(63.2 \%)$ patients with a scheduled follow-up appointment and 18,664 (36.8\%) patients with no scheduled follow-up. Of the patients with a scheduled followup, $28,313(88.2 \%)$ patients arrived to a follow-up appointment, $3149(9.8 \%)$ missed all their appointments, and 646 $(2.0 \%)$ were readmitted prior to their appointments. Overall, 3680 patients were readmitted within 30 days of discharge (readmission rate $7.3 \%$ ). When stratified by their follow-up appointment status, patients who arrived at a follow-up were readmitted least often (6.0\% [95\% CI 5.75-6.31]); patients without follow-up scheduled had a readmission rate of $8.8 \%$ (95\% CI 8.44-9.25); and patients who missed a scheduled appointment were readmitted most often with a readmission rate of $10.3 \%$ (95\% CI 9.28-11.40).

We first examined patient characteristics by scheduled appointment status (Table 1). Patients with a scheduled follow-up were younger, had a lower final LACE score,

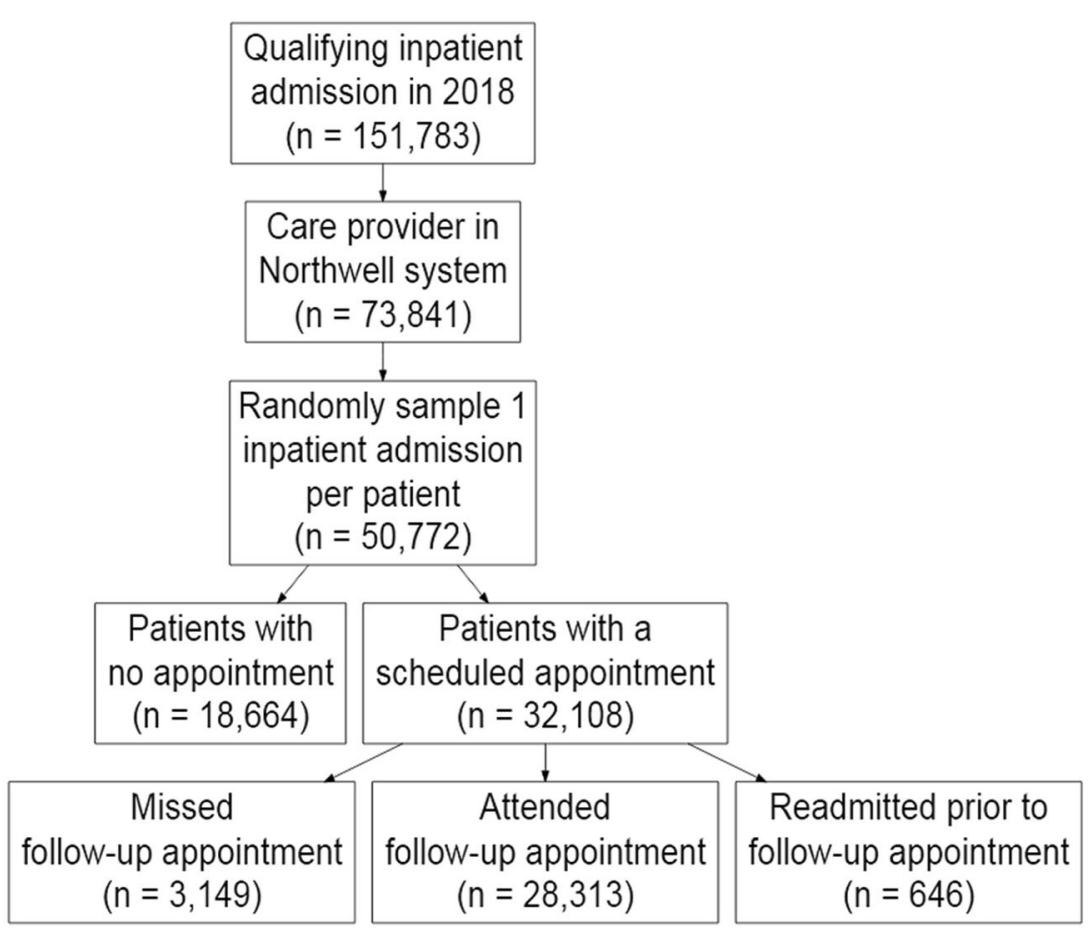

Figure 1 Flow chart of study population. 
and had a lower 30-day readmission rate compared to those with no follow-up appointment scheduled ( $p$ value $<0.001)$. When we examined patients by arrival status to scheduled appointment (Table 2), those who arrived at their appointment tended to be younger, have a lower LACE score, were more frequently admitted to a surgical service (versus medical) and a tertiary facility (versus community), and were discharged home more often than patients without follow-up ( $p$ value $<0.001)$.

\section{Characteristics of Patients Readmitted in $\mathbf{3 0}$ Days Post-discharge}

We found that a lower percentage of patients who were readmitted within 30 days of discharge arrived to a follow-up appointment compared to patients who were not readmitted $(46.4 \%$ vs. $57.3 \%, p$ value $<0.001)$. Also, a higher percentage of patients who were readmitted had no follow-up scheduled $(44.8 \%)$ compared to those who were not readmitted $(36.6 \%)$. Other demographic characteristics associated with 30-day readmission included being male $(49.4 \%$ vs. $43.6 \%, p<$ $0.001)$ and older age (81 years or older) $(26.2 \%$ vs. $21.1 \%, p<0.001)$. Clinical characteristics associated with 30-day readmission were LACE Score, discharge disposition, and inpatient service specialty (all $p$ values $<0.001$ ) (Table 3).

\section{Hospital Readmission at 7, 14, 21, and 28 days}

To examine the significance of readmission by follow-up appointment status at 7, 14, 21, and 28 days post-discharge, we ran a fully adjusted Cox model for (1) arrived at follow-up and (2) scheduled but missed follow-up compared to (3) no follow-up appointment adjusting for covariates (Table 4). In order to examine how appointment status changes from week to week, we used a step function in the Cox proportional hazards model. Patients who arrived at their appointment in the first week following hospital discharge were significantly less likely to be readmitted than those not having any followup. This risk reduction was significant in both patients discharged from the medical service (adjusted hazard ratio [aHR] 0.57 [95\% CI 0.47-0.69], $p<0.001$ ) and the surgical service (aHR 0.58 [95\% CI 0.44-0.75], $p<0.001$ ). Patients discharged from the medical service who arrived at their follow-up appointment had increased likelihood of readmission in both weeks 3 and 4 post-discharge compared to patients with no follow-up (week 3 aHR 1.29 [95\% CI 1.101.51], $p<0.001$; week 4 aHR 1.46 [95\% CI 1.26-1.70], $p<$ 0.001 ). A sensitivity analysis, which included patients who did not have any ambulatory care visit at the health system within the past 18 months, showed that the risk of readmission remained decreased for patients who had follow-up visits within 1 week (medical service aHR 0.61 [95\% CI 0.52 0.73 ], $p<0.001$; surgical service aHR 0.69 [95\% CI 0.54

Table 1 Characteristics of Patients Discharged with and Without a Follow-up Appointment

\begin{tabular}{|c|c|c|c|c|}
\hline & All patients & With an appointment & Without appointment & $p$ value \\
\hline Number of patients & 50,772 & 32,108 & 18,664 & \\
\hline 30-day readmission, No. (\%) & $4326(8.5)$ & $2676(8.3)$ & $1650(8.8)$ & 0.05 \\
\hline Female, No. (\%) & $28,378(55.9)$ & $17,744(55.3)$ & $10,634(57.0)$ & $<0.001$ \\
\hline \multicolumn{5}{|l|}{ Age, No. $(\%)$} \\
\hline $21-40$ & $4293(8.5)$ & $2824(8.8)$ & $1469(7.9)$ & \multirow[t]{4}{*}{$<0.001$} \\
\hline $41-60$ & $12,643(24.9)$ & $8488(26.4)$ & $4155(22.3)$ & \\
\hline $61-80$ & $22,899(45.1)$ & $15,087(47.0)$ & $7812(41.9)$ & \\
\hline $81+$ & $10,937(21.5)$ & $5709(17.8)$ & $5228(28.0)$ & \\
\hline \multicolumn{5}{|l|}{ Race/ethnicity, No. (\%) } \\
\hline White + Non-Hispanic & $30,772(60.6)$ & $19,163(59.7)$ & $11,609(62.2)$ & \multirow[t]{6}{*}{$<0.001$} \\
\hline Black + Non-Hispanic & $7924(15.6)$ & $4897(15.3)$ & $3027(16.2)$ & \\
\hline Other/Multiracial & $3199(6.3)$ & $2096(6.5)$ & $1103(5.9)$ & \\
\hline Hispanic & $4979(9.8)$ & $3284(10.2)$ & $1695(9.1)$ & \\
\hline Asian & $2900(5.7)$ & $1986(6.2)$ & $914(4.9)$ & \\
\hline Unknown & $998(2.0)$ & $682(2.1)$ & $316(1.7)$ & \\
\hline \multicolumn{5}{|l|}{ Final LACE Score, mean (SD) } \\
\hline L component & $3.62(1.35)$ & $3.58(1.34)$ & $3.68(1.36)$ & \multirow[t]{4}{*}{$<0.001$} \\
\hline A component & $2.00(1.41)$ & $1.76(1.48)$ & $2.43(1.18)$ & \\
\hline C component & $2.96(1.88)$ & $2.86(1.88)$ & $3.14(1.86)$ & \\
\hline E component & $1.64(1.56)$ & $1.55(1.55)$ & $1.77(1.57)$ & \\
\hline \multicolumn{5}{|l|}{ Discharge disposition, No. (\%) } \\
\hline Home & $35,651(70.2)$ & $23,667(73.7)$ & $11,984(64.2)$ & \multirow{6}{*}{$<0.001$} \\
\hline Home care & $7048(13.9)$ & $4750(14.8)$ & $2298(12.3)$ & \\
\hline Skilled nursing facility & $4400(8.7)$ & $1873(5.8)$ & $2527(13.5)$ & \\
\hline Rehab & $2662(5.2)$ & $1427(4.4)$ & $1235(6.6)$ & \\
\hline Other & $684(1.3)$ & $266(0.8)$ & $418(2.2)$ & \\
\hline Against medical advice & $327(0.6)$ & $125(0.4)$ & $202(1.1)$ & \\
\hline Length of stay, mean (SD) & $4.00[2.00,6.00]$ & $4.00[2.00,6.00]$ & $4.00[3.00,6.00]$ & $<0.001$ \\
\hline \multicolumn{5}{|c|}{ Inpatient service specialty, No. $(\%)$} \\
\hline Medicine & $32,762(64.5)$ & $17,931(55.8)$ & $14,831(79.5)$ & \multirow[t]{3}{*}{$<0.001$} \\
\hline Surgery & $17,822(35.2)$ & $14,092(43.9)$ & $3730(20.0)$ & \\
\hline Other & $188(0.4)$ & $85(0.3)$ & $103(0.6)$ & \\
\hline Tertiary facility, No. (\%) & $37,552(74.0)$ & $25,292(78.8)$ & $12,260(65.7)$ & $<0.001$ \\
\hline
\end{tabular}


Table 2 Characteristics of Patients with an Appointment Who Arrived or Missed the Appointment

\begin{tabular}{|c|c|c|c|c|c|}
\hline & $\begin{array}{l}\text { All patients with an } \\
\text { appointment }\end{array}$ & $\begin{array}{l}\text { Arrived at } \\
\text { appointment }\end{array}$ & $\begin{array}{l}\text { Missed } \\
\text { appointment }\end{array}$ & $\begin{array}{l}\text { Readmitted } \\
\text { prior }\end{array}$ & $p$ value $*$ \\
\hline Number of patients & 32,108 & 28,313 & 3149 & 646 & \\
\hline $\begin{array}{l}30 \text {-day readmission, No. } \\
(\%)\end{array}$ & $2676(8.3)$ & $1706(6.0)$ & $324(10.3)$ & $646(100)$ & $<0.001$ \\
\hline Female, No. (\%) & $17,744(55.3)$ & $15,673(55.4)$ & $1749(55.5)$ & $322(49.8)$ & 0.002 \\
\hline \multicolumn{6}{|l|}{ Age, No. $(\%)$} \\
\hline $21-40$ & $2824(8.8)$ & $2537(9.0)$ & $249(7.9)$ & $38(5.9)$ & \multirow[t]{4}{*}{$<0.001$} \\
\hline $41-60$ & $8488(26.4)$ & $7639(27.0)$ & $704(22.4)$ & $145(22.4)$ & \\
\hline $61-80$ & $15,087(47.0)$ & $13,479(47.6)$ & $1305(41.4)$ & $303(46.9)$ & \\
\hline $81+$ & $5709(17.8)$ & $4658(16.5)$ & $891(28.3)$ & $160(24.8)$ & \\
\hline \multicolumn{6}{|l|}{ Race/ethnicity, No. (\%) } \\
\hline White + Non-Hispanic & $19,163(59.7)$ & $16,923(59.8)$ & $1863(59.2)$ & $377(58.4)$ & \multirow[t]{6}{*}{$<0.001$} \\
\hline Black + Non-Hispanic & $4897(15.3)$ & $4209(14.9)$ & $580(18.4)$ & $108(16.7)$ & \\
\hline Other/multiracial & $2096(6.5)$ & $1890(6.7)$ & $165(5.2)$ & $41(6.3)$ & \\
\hline Hispanic & $3284(10.2)$ & $2899(10.2)$ & $315(10.0)$ & $70(10.8)$ & \\
\hline Asian & $1986(6.2)$ & $1783(6.3)$ & $162(5.1)$ & $41(6.3)$ & \\
\hline Unknown & $682(2.1)$ & $609(2.2)$ & $64(2.0)$ & $9(1.4)$ & \\
\hline \multicolumn{6}{|c|}{ Final LACE Score, mean (SD) } \\
\hline L component & $3.58(1.34)$ & $3.52(1.32)$ & $3.97(1.40)$ & $4.12(1.46)$ & \multirow[t]{4}{*}{$<0.001$} \\
\hline A component & $1.76(1.48)$ & $1.66(1.49)$ & $2.55(1.08)$ & $2.20(1.33)$ & \\
\hline $\mathrm{C}$ component & $2.86(1.88)$ & $2.77(1.88)$ & $3.48(1.78)$ & $3.58(1.76)$ & \\
\hline E component & $1.55(1.55)$ & $1.48(1.53)$ & $1.95(1.58)$ & $2.88(1.25)$ & \\
\hline \multicolumn{6}{|c|}{ Discharge disposition, No. (\%) } \\
\hline Home & $23,667(73.7)$ & $21,373(75.5)$ & $1869(59.4)$ & $425(65.8)$ & \multirow[t]{6}{*}{$<0.001$} \\
\hline Home care & $4750(14.8)$ & $4248(12.0)$ & $382(12.1)$ & $120(18.6)$ & \\
\hline Skilled nursing facility & $1873(5.8)$ & $1285(4.5)$ & $533(16.9)$ & $55(8.5)$ & \\
\hline Rehab & $1427(4.4)$ & $1112(3.9)$ & $281(8.9)$ & $34(5.3)$ & \\
\hline Other & $266(0.8)$ & $201(0.7)$ & $55(1.7)$ & $10(1.5)$ & \\
\hline Against medical advice & $125(0.4)$ & $94(0.3)$ & $29(0.9)$ & $2(0.3)$ & \\
\hline Length of stay, mean (SD) & $4.00[2.00,6.00]$ & $4.00[2.00,6.00]$ & $5.00[3.00,8.00]$ & $5.00[3.00,9.00]$ & $<0.001$ \\
\hline \multicolumn{6}{|c|}{ Inpatient service specialty, No. (\%) } \\
\hline Medicine & $17,931(55.8)$ & $14,919(52.7)$ & $2562(81.4)$ & $450(69.7)$ & \multirow[t]{3}{*}{$<0.001$} \\
\hline Surgery & $14,092(43.9)$ & $13,330(47.1)$ & $570(18.1)$ & $192(29.7)$ & \\
\hline Other & $85(0.3)$ & $64(0.2)$ & $17(0.5)$ & $4(0.6)$ & \\
\hline Tertiary facility (\%) & $25,292(78.8)$ & $22,395(79.1)$ & $2379(75.5)$ & $518(80.2)$ & $<0.001$ \\
\hline
\end{tabular}

${ }^{*} p$ values comparing those who arrived versus missed the follow-up appointment

0.87], $p=002$ ). Patients discharged from the medical service who arrived at their follow-up appointments had increased likelihood of readmission starting week 2, compared to patients with no follow-up (week 2 aHR 1.25 [95\% CI 1.11$1.42], p<0.001)$.

\section{DISCUSSION}

Patients who arrived at post-discharge appointments had a lower rate of 30-day hospital readmission compared with patients missing their follow-up visits and patients with no follow-up scheduled. When adjusting for covariates, patients who arrived at their scheduled follow-up appointments had decreased risk of readmission only in the first week postdischarge. We also found that patients discharged from the medical service with follow-ups appointments in 3 or 4 weeks post-discharge had increased risk of readmission. For patients with later follow-up visits, the lag between hospitalization and follow-up might have reduced opportunities to prevent readmission.

There are multiple factors that may affect when and whether follow-up appointments are scheduled. Timing of the scheduled visit may have been influenced by primary care office capacity, which may be lower for practices serving medically or socially complex patients. Therefore, despite the need to follow-up soon after their hospitalizations, patients who get care from busy primary care offices may not able to get earlier appointments. A higher percentage of patients who were discharged home had a follow-up appointment, compared to patients who were not discharged home. This might be because the patients who were discharged to care facility or subacute rehabilitation are cared by a physician in the facility and might not need a follow-up appointment. Lastly, patients whose follow-up visits are at week 3 and 4 post-discharge may have had an unexpected clinical need to seek medical care unrelated to the index hospitalization and chose to schedule an appointment later in the follow-up period. ${ }^{23}$

Our study shows several areas in which 30-day readmission rates can be improved. Despite studies showing improved health outcomes with a post-discharge follow-up appointment, one-third of hospitalized patients did not have any scheduled follow-up appointment in our analysis. These findings suggest that hospitals can potentially improve 30 -day readmission by identifying patients at high risks for 30-day readmissions and coordinating post-discharge follow-up appointments for patients during hospitalization. A development of a 30-day risk calculator would be helpful to prioritize whom to schedule for follow-up in 1 week. We also found that $10 \%$ of patients did not show up to their appointment. It will be important to assess the factors, particularly social determinants of health, which may be affecting arrival to the appointment. 
Table 3 Characteristics of Patients by 30-Day Readmission Outcome

\begin{tabular}{|c|c|c|c|}
\hline & $\begin{array}{l}\text { Not readmitted } \\
\text { in } 30 \text { days }\end{array}$ & $\begin{array}{l}\text { Readmitted in } \\
30 \text { days }\end{array}$ & $\begin{array}{l}p \\
\text { value }\end{array}$ \\
\hline $\begin{array}{l}\text { Number of } \\
\text { patients }\end{array}$ & 46,446 & 3680 & \\
\hline \multicolumn{4}{|c|}{ Appointment group, No. (\%) } \\
\hline $\begin{array}{l}\text { Arrived at follow- } \\
\mathrm{up}(\mathrm{s})\end{array}$ & $26,607(57.3)$ & $1706(46.4)$ & $\begin{array}{l}< \\
0.001\end{array}$ \\
\hline $\begin{array}{l}\text { Missed follow- } \\
\text { up(s) }\end{array}$ & $2825(6.1)$ & $324(8.8)$ & \\
\hline No appointment & $17,014(36.6)$ & $1650(44.8)$ & \\
\hline Female, No. (\%) & $26,194(56.4)$ & $1862(50.6)$ & $\begin{array}{l}< \\
0.001\end{array}$ \\
\hline \multicolumn{4}{|l|}{ Age, No. $(\%)$} \\
\hline $21-40$ & $4017(8.6)$ & $238(6.5)$ & $<$ \\
\hline $41-60$ & $11,714(25.2)$ & $784(21.3)$ & 0.001 \\
\hline $61-80$ & $20,904(45.0)$ & $1692(46.0)$ & \\
\hline $81+$ & $9811(21.1)$ & $966(26.2)$ & \\
\hline \multicolumn{4}{|c|}{ Race/ethnicity, No. (\%) } \\
\hline $\begin{array}{l}\text { White + Non- } \\
\text { Hispanic }\end{array}$ & $28,111(60.5)$ & $2284(62.1)$ & 0.003 \\
\hline $\begin{array}{l}\text { Black + Non- } \\
\text { Hispanic }\end{array}$ & $7195(15.5)$ & $621(16.9)$ & \\
\hline Other/multiracial & $2955(6.4)$ & $203(5.5)$ & \\
\hline Hispanic & $4584(9.9)$ & $325(8.8)$ & \\
\hline Asian & $2677(5.8)$ & $182(4.9)$ & \\
\hline Unknown & $924(2.0)$ & $65(1.8)$ & \\
\hline \multicolumn{4}{|c|}{ Final LACE Score, mean (SD) } \\
\hline L component & $3.57(1.33)$ & $4.08(1.42)$ & $<$ \\
\hline A component & $1.97(1.42)$ & $2.35(1.24)$ & 0.001 \\
\hline C component & $2.89(1.88)$ & $3.77(1.67)$ & \\
\hline E component & $1.52(1.54)$ & $2.82(1.30)$ & \\
\hline \multicolumn{4}{|c|}{ Discharge disposition, No. (\%) } \\
\hline Home & $32,890(70.8)$ & $2336(63.5)$ & $<$ \\
\hline Home care & $6237(13.4)$ & $691(18.8)$ & 0.001 \\
\hline $\begin{array}{l}\text { Skilled nursing } \\
\text { facility }\end{array}$ & $3999(8.6)$ & $346(9.4)$ & \\
\hline Rehab & $2417(5.2)$ & $211(5.7)$ & \\
\hline Other & $183(0.4)$ & $19(0.5)$ & \\
\hline $\begin{array}{l}\text { Against medical } \\
\text { advice }\end{array}$ & $284(0.6)$ & $41(1.1)$ & \\
\hline $\begin{array}{l}\text { Length of stay, } \\
\text { median [IQR] }\end{array}$ & $4.00[2.00,6.00]$ & $5.00[3.00,8.00]$ & $\begin{array}{l}< \\
0.001\end{array}$ \\
\hline \multicolumn{4}{|c|}{ Inpatient service specialty, No. (\%) } \\
\hline Medicine & $29,557(63.6)$ & $2755(74.9)$ & $<$ \\
\hline Surgery & $16,724(36.0)$ & $906(24.6)$ & 0.001 \\
\hline Other & $165(0.4)$ & $19(0.5)$ & \\
\hline $\begin{array}{l}\text { Tertiary facility } \\
(\%)\end{array}$ & $34,310(73.9)$ & $2724(74.0)$ & $\begin{array}{l}< \\
0.001\end{array}$ \\
\hline
\end{tabular}

We further found a cohort of patients who, despite having follow-up care scheduled, were readmitted prior to their appointment. This group might be composed of high healthcare utilizers with high risk of readmission, as evidenced by the high number of emergency department use in the prior 6 months, an elevated LACE index, and their quick readmission (frequently within less than a week). This suggests that there may be patient characteristics, including behavior patterns that may require intervention other than follow-up appointments. Previous studies have found that a patient's stability at the time of discharge is a key predictor of early readmission, and assessing postdischarge stability is an important component of readmission reduction. ${ }^{23,33}$ Also, early post-discharge follow-up visits, preferably within 1 week, have been associated with reduced readmission. ${ }^{23,34}$ Strategies to reduce 30-day readmission for this subgroup of patients may differ from strategies to reduce 30-day readmission for other groups of patients.
Table 4 Cumulative Likelihood (Hazard Ratio [95\% Confidence Interval]) of Hospital Readmission at 1, 2, 3, and 4 Weeks Posthospitalization by Inpatient Service

\begin{tabular}{|c|c|c|}
\hline \multicolumn{3}{|l|}{ A. Medical service } \\
\hline & Hazard ratio $[95 \% \mathrm{CI}]$ & $p$ value \\
\hline \multicolumn{3}{|l|}{ Follow-up week 1} \\
\hline Arrived at follow-up & $0.57[0.47-0.69]$ & $<0.001$ \\
\hline Scheduled/missed follow-up & $0.74[0.55-0.98]$ & 0.04 \\
\hline \multirow{2}{*}{\multicolumn{3}{|c|}{ Follow-up week 2}} \\
\hline & & \\
\hline Arrived at Follow-up & $1.12[0.97-1.31]$ & 0.13 \\
\hline Scheduled/Missed Follow-up & $1.20[0.93-1.54]$ & 0.15 \\
\hline No Follow-up & 1 [Reference] & \\
\hline \multicolumn{3}{|l|}{ Follow-up week 3} \\
\hline Arrived at follow-up & $1.29[1.10-1.51]$ & 0.001 \\
\hline Scheduled/missed follow-up & $1.21[0.93-1.57]$ & 0.16 \\
\hline No follow-up & 1 [Reference] & \\
\hline \multicolumn{3}{|l|}{ Follow-up week 4} \\
\hline Arrived at follow-up & $1.46[1.26-1.70]$ & $<0.001$ \\
\hline Scheduled/missed follow-up & $1.31[1.02-1.68]$ & 0.04 \\
\hline No follow-up & 1 [Reference] & \\
\hline \multicolumn{3}{|l|}{ B. Surgical service } \\
\hline & Hazard ratio $[95 \% \mathrm{CI}]$ & $p$ value \\
\hline \multicolumn{3}{|l|}{ Follow-up week 1} \\
\hline Arrived at follow-up & $0.58[0.44-0.75]$ & $<0.001$ \\
\hline Scheduled/missed follow-up & $0.93[0.60-1.44]$ & 0.74 \\
\hline No follow-up & 1 [Reference] & \\
\hline \multicolumn{3}{|l|}{ Follow-up week 2} \\
\hline Arrived at follow-up & $0.97[0.76-1.24]$ & 0.80 \\
\hline Scheduled/missed follow-up & $0.93[0.54-1.60]$ & 0.80 \\
\hline No follow-up & 1 [Reference] & \\
\hline \multicolumn{3}{|l|}{ Follow-up week 3} \\
\hline Arrived at follow-up & $1.24[0.90-1.71]$ & 0.19 \\
\hline Scheduled/missed follow-up & $0.93[0.46-1.90]$ & 0.85 \\
\hline No follow-up & 1 [Reference] & \\
\hline \multicolumn{3}{|l|}{ Follow-up week 4} \\
\hline Arrived at follow-up & $1.23[0.89-1.71]$ & 0.21 \\
\hline Scheduled/missed follow-up & $1.15[0.58-2.28]$ & 0.70 \\
\hline No follow-up & 1 [Reference] & \\
\hline
\end{tabular}

Our study has several limitations. Although we tried to identify patients who would follow-up with the same health system by limiting those who had a previous ambulatory visit within the 18 months, there may be a subgroup of patients who receive follow-up with an out-of-network provider. In addition, we cannot be completely certain that we captured all of the 30-day readmissions because patients can have a readmission at a non-health system facility. Notably, a previous study has shown that a majority of the patients hospitalized at this health system's hospitals will return to hospitals within the same health system. ${ }^{35} \mathrm{We}$ also do not have information when appointments were scheduled in relation to the hospitalization (during the hospital discharge process vs. post-discharge). While we attempted to adjust for common risk factors in our models, additional confounders may exist such as social determinants of health. ${ }^{36,37}$ For example, patients with financial hardship or homelessness will have more difficulty scheduling and attending these follow-up visits and, thus, increase their likelihood of readmission. 


\section{Conclusion}

Lowering 30-day readmission rates has been a priority of many health systems as this is a key metric of hospital quality and performance, and financial penalties can be incurred with above-average readmission rates. In our study examining association between post-discharge follow-up and 30-day readmission, we found that a followup appointment within 7 days of discharge is significantly associated with lower readmission risk across all patient types, including medical and surgical patients. Identifying high-risk patients, scheduling timely follow-up care, and ensuring these patients actually arrive for their scheduled visits are crucial steps to reduce unwarranted hospital readmissions.

Supplementary Information The online version contains supplementary material available at https://doi.org/10.1007/s11606-02006569-5.

Acknowledgments: We thank Dr. Sumit Mohan for his generous and elucidative statistical guidance.

Corresponding Author: Jamie S. Hirsch, MD, MA, MSB; Department of Information Services, Northwell Health, Lake Success, NY, USA (e-mail: jhirsch8@northwell.edu).

\section{Compliance with Ethical Standards:}

Conflict of Interest: The authors declare that they do not have a conflict of interest.

Disclaimer: The views expressed in this article are those of the authors and do not necessarily represent the views of Northwell Health, Feinstein Institutes for Medical Research, and Donald and Barbara Zucker School of Medicine at Hofstra/Northwell

\section{REFERENCES}

1. Clancy CM. Reengineering hospital discharge: a protocol to improve patient safety, reduce costs, and boost patient satisfaction. Am J Med Qual. 2009;24(4):344-6.

2. Coleman EA, Smith JD, Raha D, Min SJ. Posthospital medication discrepancies: prevalence and contributing factors. Arch Intern Med. 2005; 165(16): 1842-7.

3. Jencks SF, Williams MV, Coleman EA. Rehospitalizations among patients in the Medicare fee-for-service program. N Engl J Med. 2009;360(14): 1418-28.

4. 2019;Pages. Accessed at Centers for Medicare \& Medicaid Services at https://www.cms.gov/Medicare/Medicare-Fee-for-Service-Payment/ AcuteInpatientPPS/Readmissions-Reduction-Program.html on May 8, 2019.

5. Ahmad FS, Metlay JP, Barg FK, Henderson RR, Werner RM. Identifying hospital organizational strategies to reduce readmissions. Am J Med Qual. 2013;28(4):278-85.

6. Myers LC, Faridi MK, Hasegawa K, Hanania NA, Camargo CA, Jr. The Hospital Readmissions Reduction Program and Readmissions for Chronic Obstructive Pulmonary Disease, 2006-2015. Ann Am Thorac Soc. 2019

7. Gai Y, Pachamanova D. Impact of the Medicare hospital readmissions reduction program on vulnerable populations. BMC Health Serv Res. 2019;19(1):837.

8. Ferro EG, Secemsky EA, Wadhera RK, Choi E, Strom JB, Wasfy JH, et al. Patient readmission rates for all insurance types after implementation of the Hospital Readmissions Reduction Program. Health Aff (Millwood). 2019;38(4):585-93.
9. Hansen LO, Young RS, Hinami K, Leung A, Williams MV. Interventions to reduce 30-day rehospitalization: a systematic review. Ann Intern Med. 2011;155(8):520-8

10. Peikes D, Chen A, Schore J, Brown R. Effects of care coordination on hospitalization, quality of care, and health care expenditures among Medicare beneficiaries: 15 randomized trials. JAMA. 2009;301(6):603-18.

11. Jack BW, Chetty VK, Anthony D, Greenwald JL, Sanchez GM, Johnson AE, et al. A reengineered hospital discharge program to decrease rehospitalization: a randomized trial. Ann Intern Med. 2009;150(3):178-87.

12. Mitchell SE, Gardiner PM, Sadikova E, Martin JM, Jack BW, Hibbard JH, et al. Patient activation and 30-day post-discharge hospital utilization. J Gen Intern Med. 2014;29(2):349-55.

13. Misky GJ, Wald HL, Coleman EA. Post-hospitalization transitions: examining the effects of timing of primary care provider follow-up. J Hosp Med. 2010;5(7):392-7.

14. Lin CY, Barnato AE, Degenholtz HB. Physician follow-up visits after acute care hospitalization for elderly Medicare beneficiaries discharged to noninstitutional settings. J Am Geriatr Soc. 2011;59(10):1947-54.

15. Khera R, Horwitz LI, Lin Z, Krumholz HM. Publicly reported readmission measures and the Hospital Readmissions Reduction Program: a false equivalence? Ann Intern Med. 2018;168(9):670-1.

16. Feltner C, Jones CD, Cene CW, Zheng ZJ, Sueta CA, CokerSchwimmer EJ, et al. Transitional care interventions to prevent readmissions for persons with heart failure: a systematic review and meta-analysis. Ann Intern Med. 2014;160(11):774-84.

17. Hernandez AF, Greiner MA, Fonarow GC, Hammill BG, Heidenreich PA, Yancy CW, et al. Relationship between early physician follow-up and 30-day readmission among Medicare beneficiaries hospitalized for heart failure. JAMA. 2010;303(17):1716-22.

18. Hubbard M, Frost S, Siu K, Guon N, Esposito D. Association between outpatient visits following hospital discharge and readmissions among Medicare beneficiaries with atrial fibrillation and other chronic conditions. Am J Med Qual. 2014;29(3):206-12.

19. Hess CN, Shah BR, Peng SA, Thomas L, Roe MT, Peterson ED. Association of early physician follow-up and 30-day readmission after non-ST-segment-elevation myocardial infarction among older patients. Circulation. 2013;128(11):1206-13.

20. Dharmarajan K, Wang Y, Lin Z, Normand ST, Ross JS, Horwitz LI, et al. Association of changing hospital readmission rates with mortality rates after hospital discharge. JAMA. 2017;318(3):270-8.

21. Gupta A, Allen LA, Bhatt DL, Cox M, DeVore AD, Heidenreich PA, et al. Association of the Hospital Readmissions Reduction Program implementation with readmission and mortality outcomes in heart failure. JAMA Cardiol. 2018;3(1):44-53.

22. Fonarow GC, Konstam MA, Yancy CW. The Hospital Readmission Reduction Program is associated with fewer readmissions, more deaths: time to reconsider. J Am Coll Cardiol. 2017;70(15):1931-4.

23. Graham KL, Auerbach AD, Schnipper JL, Flanders SA, Kim CS, Robinson EJ, et al. Preventability of early versus late hospital readmissions in a national cohort of general medicine patients. Ann Intern Med. 2018;168(11):766-74.

24. Sinha S, Seirup J, Carmel A. Early primary care follow-up after ED and hospital discharge - does it affect readmissions? Hosp Pract (1995). 2017;45(2):51-7.

25. Saunders RS, Fernandes-Taylor S, Rathouz PJ, Saha S, Wiseman JT, Havlena $\mathbf{J}$, et al. Outpatient follow-up versus 30-day readmission among general and vascular surgery patients: a case for redesigning transitional care. Surgery. 2014;156(4):949-56.

26. van Walraven C, Dhalla IA, Bell C, Etchells E, Stiell IG, Zarnke K, et al. Derivation and validation of an index to predict early death or unplanned readmission after discharge from hospital to the community. CMAJ. 2010;182(6):551-7.

27. Schoenfeld D. Partial residuals for the proportional hazards regression model. Biometrika. 1982 April 1;69(1):239-41.

28. Wickham HF, R.; Henry, L.; Müller, K. . dplyr: a grammar of data manipulation. R package. 0.7 ed; 2017.

29. Wickham H. ggplot2: elegant graphics for data analysis. Springer. 2016 June 8.

30. Grolemund GW, H. Dates and times made easy with lubridate. Journal of Statistical Software. 2011;40(3):1-25.

31. Therneau TMG, P. M. Modeling survival data: extending the Cox model. Springer Science \& Business Media. 2013 November 11.

32. Kassambara AK, M.; Biecek, P. survminer: drawing survival curves using 'ggplot2'. R package version 0.3; 2017. 
33. Lavenberg JG, Leas B, Umscheid CA, Williams K, Goldmann DR, Kripalani S. Assessing preventability in the quest to reduce hospital readmissions. J Hosp Med. 2014;9(9):598-603.

34. Shen E, Koyama SY, Huynh DN, Watson HL, Mittman B, Kanter MH, et al. Association of a dedicated post-hospital discharge follow-up visit and 30-day readmission risk in a Medicare advantage population. JAMA Intern Med. 2017;177(1):132-5.

35. Nouryan CN, Morahan S, Pecinka K, Akerman M, Lesser M, Chaikin D, et al. Home telemonitoring of community-dwelling heart failure patients after home care discharge. Telemed J E Health. 2019;25(6):447-54.
36. Meddings J, Reichert H, Smith SN, Iwashyna TJ, Langa KM, Hofer TP, et al. The impact of disability and social determinants of health on condition-specific readmissions beyond Medicare risk adjustments: a cohort study. J Gen Intern Med. 2017;32(1):71-80.

37. Navathe AS, Zhong F, Lei VJ, Chang FY, Sordo M, Topaz M, et al. Hospital readmission and social risk factors identified from physician notes. Health Serv Res. 2018;53(2):1110-36.

Publisher's Note: Springer Nature remains neutral with regard to jurisdictional claims in published maps and institutional affiliations. 